\title{
BMJ Open Managing cancer in context of pandemic: a qualitative study to explore the emotional and behavioural responses of patients with cancer and their caregivers to COVID-19
}

To cite: Chia JMX, Goh ZZS, Chua ZY, et al. Managing cancer in context of pandemic: a qualitative study to explore the emotional and behavioural responses of patients with cancer and their caregivers to COVID-19. BMJ Open 2021;11:e041070. doi:10.1136/ bmjopen-2020-041070

- Prepublication history and additional material for this paper is available online. To view these files, please visit the journal online (http://dx.doi.org/10. 1136/bmjopen-2020-041070).

Received 29 May 2020 Revised 26 November 2020 Accepted 11 January 2021

A Check for updates

(c) Author(s) (or their employer(s)) 2021. Re-use permitted under CC BY-NC. No commercial re-use. See rights and permissions. Published by BMJ.

${ }^{1}$ Centre for Population Health Sciences, Lee Kong Chian School of Medicine, Nanyang Technological University Singapore, Singapore 2Division of Medical Oncology, National Cancer Centre Singapore, Singapore

Correspondence to A/Prof Konstadina Griva; konstadina.griva@ntu.edu. sg and

A/Prof Joanne Yuen Yie Ngeow; joanne.ngeow@ntu.edu.sg

\section{ABSTRACT}

Objectives Having to access life-sustaining treatment during the emerging COVID-19 outbreak has placed patients with cancer at an especially vulnerable position notwithstanding their immunocompromised condition. The present study aimed to elucidate cancer patients' and their caregivers' experiences during this outbreak.

Design Face-to-face semistructured interviews were conducted.

Setting A tertiary cancer care facility.

Participants 16 patients with cancer and 14 caregivers. Inclusions criteria were: (A) diagnosed with cancer, (B) receiving active treatment or follow-ups, $(C)$ aged 21 years and above and (D) fluent in English or Mandarin.

Results Thematic analysis was conducted. Five themes were identified: heightened sense of threat, impact on healthcare experience, responsibility falls on oneself, striving for normalcy and sense of safety and trust. Heightened threat of COVID-19 was more pronounced in patients and linked to vulnerability and fear, uncertainty and actions of socially irresponsible others. Dominant in their healthcare experience was prioritising cancer and treatment amidst heightened threat and anticipatory worry about treatment disruptions. Both noted on the importance of taking responsibility for one's health, with caregivers reporting a reinforced sense of duty towards patients. They strived to maintain normalcy by viewing COVID-19 as beyond personal control, downplaying and living life as usual. Their resolve was supported by a sense of safety from the actions of authorities, hospitals and trust towards healthcare providers.

Conclusions Cancer intensifies threat and the emotional impact of COVID-19 and may trigger specific concerns related to treatment. Psychoeducation interventions led by healthcare providers over digital platforms could help address cancer-specific concerns and support patients and caregivers during the pandemic.

\section{BACKGROUND}

COVID-19 first hit Singapore's shores on 23 January 2020. In the months that followed,
Strengths and limitations of this study

- A timely qualitative analysis of the emotional and behavioural impact of COVID-19 on cancer patients and caregivers.

- This study highlights the heightened threat and risks patients with cancer face during the COVID-19 outbreak and proposes the need for healthcare services to incorporate psychosocial support on cancer management.

- The rapidly evolving nature of the COVID-19 situation limits the generalisability of the findings to later phases of the pandemic.

- Future qualitative work at later phases of the pandemic and with various population groups is warranted.

COVID-19 was declared a pandemic by the WHO after its rampant spread to most of the world. Infectious disease outbreaks such as COVID-19 present major challenges to global public and individual health. No less important are the psychological costs and mental health implications. Prior work in SARS and H1N1 alongside emerging work on COVID-19 documented adverse psychological responses and psychiatric morbidity for frontline healthcare workers, infected patients and the general population that may persist over time. ${ }^{1-8}$ Emotional responses such as fear and anxiety have been shown to influence actions, some of which may be undesirable. Selfisolation, stigmatisation, non-disclosure or non-treatment seeking behaviours noted in the Ebola outbreak ${ }^{9}$ contributed to community spread and compromised efficiency of healthcare systems. ${ }^{10} 11$ In response to the outbreak, Singapore implemented several precautionary measures including quarantine 
for travellers, contact tracing for infected patients and prioritising healthcare resources to treating patients with COVID-19. While the emotional and behavioural impact of infectious outbreaks are well-documented for the general population, infection survivors and frontline healthcare workers, the literature on patient populations is scarce. ${ }^{1-5}$

For patients with cancer, treatment is often nondeferrable and cannot be delivered over telemedicine. This means they are potentially exposed to the risks of infection at the clinics and while being outside. Furthermore, immunosuppression from cancer treatments such as chemotherapy could result in increased vulnerability to infection and rapid deterioration of health should they be infected. ${ }^{12} 13$

Psychological distress, which may be manifested as a variety of negative emotions from shock, anger, denial to anxiety, depression and fear of recurrence ${ }^{14}$ has been documented in $29 \%-43 \%$ of patients with cancer. ${ }^{15}$ Emotional burden and distress is evident across all stages of disease from diagnosis, treatment to survivorship ${ }^{16} 17$ and extend to caregivers and family members. ${ }^{17-19}$ Despite recognition that the COVID-19 pandemic presents greater challenges to patients with cancer and caregivers, ${ }^{20}$ the qualitative and quantitative impact of COVID-19 on their psychosocial well-being are not well understood. It is important to elucidate their experiences with treatment and specific needs during this pandemic to design and effectively optimise psychosocial care.
The objectives of this study are to explore the emotional impact of and behavioural responses to COVID-19, focusing specifically on patients with cancer and their caregivers.

\section{METHODS}

This study adopted a qualitative methodology involving semistructured interviews. The paper was structured following Consolidated criteria for Reporting Qualitative research guidelines. ${ }^{21}$

\section{Setting and participants}

Study sample included patients with cancer and caregivers recruited between 9 and 13 March 2020 from the National Cancer Centre Singapore (NCCS), a tertiary care facility serving a culturally and ethnically heterogeneous population. During the week, the outbreak was declared a pandemic and local cases rose from 160 to 200 (see table 1).

Target sample size was 15-20 individuals per group as recommended to achieve theme saturation. ${ }^{22}$ Maximum variation sampling procedures were applied to ensure diversity in terms of cancer treatment. Inclusion criteria for patients were: (A) diagnosed with any type of cancer, (B) receiving active treatment or follow-ups, (C) aged 21 years and above and (D) fluent in either English or Mandarin. Those only fluent in dialects or unable to give consent due to cognitive or psychiatric diagnoses were

Table 1 Overview of the COVID-19 situation in Singapore during study recruitment

\begin{tabular}{|c|c|c|c|c|c|c|}
\hline Date & $\begin{array}{l}\text { New cases } \\
\text { (imported) }\end{array}$ & Discharged & Overall & $\begin{array}{l}\text { Active cases } \\
\text { (in ICU) }\end{array}$ & Significant event(s) & New measures taken \\
\hline 9 March & $10(3)$ & 3 & 160 & $67(10)$ & $\begin{array}{l}7 \text { local clusters identified } \\
\text { Italian cruise ship Costa } \\
\text { Fortuna returning as } \\
\text { scheduled on } 10 \text { March } \\
2020 \text {. }\end{array}$ & \\
\hline 11 March & $12(1)$ & 3 & 178 & $82(9)$ & & \\
\hline 12 March & $9(5)$ & 0 & 187 & $91(9)$ & $\begin{array}{l}\text { COVID-19 announced a } \\
\text { pandemic by the WHO. }\end{array}$ & $\begin{array}{l}\text { Islamic Religious Council of } \\
\text { Singapore announced the } \\
\text { closure of all mosques for } \\
5 \text { days from } 13 \text { March for } \\
\text { disinfection. }\end{array}$ \\
\hline
\end{tabular}


excluded. Caregivers of eligible patients were recruited if they satisfied criteria $\mathrm{C}-\mathrm{D}$ and provided consent.

\section{Data collection}

Semistructured interviews were conducted once during follow-up appointments or active treatment at NCCS. Several measures had been implemented following the outbreak: temperature screening stations, declaration of travel and symptom checklist before entry, physical distancing at all premises, wearing of masks and restriction of visitors in clinics. Access to NCCS was only possible for NCCS staff and patients (with one accompanying caregiver). Interviewers obtained informed consent and permission to audio-record. They conducted the interviews in a private area in the outpatient clinics (three were conducted in inpatient wards) in either English or Mandarin based on participants' preference. Patients and caregivers were interviewed separately for an average of $35 \mathrm{~min}$. Interviewers included two research coordinators not involved in direct patient care (SMF and DI) and one oncologist (KYYN) with access to inpatient wards but not directly involved in the care of the patients recruited there. All interviewers had graduate qualifications and experience with qualitative methodology. Interviews were audio-recorded with field notes taken. Participants' sociodemographic and clinical characteristics were also documented. Recruitment stopped when no new themes emerged in two consecutive interviews (ie, thematic saturation).

Two interview guides (one each for patients and caregivers) were formulated based on relevant literature and expert input on clinical perspectives (JYYN and KYYN) and qualitative health research (KG). Patient and caregiver interview guides comprised similar nondirective and open-ended questions about their experiences accessing healthcare and cancer treatment during the COVID-19 outbreak (eg, perceptions and concerns about risks, emotions and behavioural responses). Questions and prompts were refined iteratively to enable novel topics to be pursued in subsequent interviews (see online supplemental material). Interview content and procedures were pilot tested with two patients and two caregivers, serving as critical reference group for data trustworthiness. ${ }^{23}$ Feedback about relevance, clarity and appropriateness of questions in the interview guide were sought from the pilot.

\section{Patient and public involvement}

Due to the rapidly evolving COVID-19 situation and measures related to patient contact, it was not possible to engage patients or the public in the development of this study. Patient and caregivers' input on all study procedures was solicited during the pilot.

\section{Analytical approach}

Thematic analysis was conducted including: familiarisation with the data, identifying initial codes, identifying initial themes, reviewing and revising themes, and naming and assigning descriptions to themes. ${ }^{24}$ Interview audio-recordings were transcribed verbatim by study team (ZYC, ZZSG and JMXC). Mandarin interviews were translated directly into English, and translations were verified. No specialised qualitative software was used. Patient and caregiver interview transcripts were coded and analysed separately by two sets of coders (patient: JMXC and ZYC; caregiver: ZZSG and KYYN) under KG's supervision. A combination of deductive and inductive coding was used. Each pair of coders independently identified codes from participant responses and confirmed agreement. The initial codes were subsequently categorised into potential (sub) themes and the subthemes into higher order themes. This process was iterative with codes, subthemes and themes reviewed against recordings and discussed and refined by coders and KG to ensure relevant and distinctiveness of resulting themes. Two codebooks were generated (one each for patients and caregivers). These were reviewed and contrasted, and only merged into a master codebook when deemed comparable. The master codebook was used to recode all interviews. When relevant, themes unique to either participant group were noted.

Trustworthiness was examined using established criteria. ${ }^{25}$ To ensure credibility, pretesting and feedback was sought before recruitment. During the interviews, participants were prompted to elaborate on their responses to ensure clarity and minimise misinterpretation by interviewers. We used investigator triangulation, in which study team discussed the axial and selective coding and data interpretation. ${ }^{26}$ Regarding the dependability and confirmability, an audit trail was kept from project start to data dissemination.

\section{RESULTS}

Of the 41 eligible individuals approached, 30 consented (16 patients and 14 caregivers; response rate $=73.2 \%$ ). Six patients and six caregivers were related. Reasons for decline included a lack of time and unwillingness to be audio-recorded. Interviews were conducted in English $(\mathrm{n}=23)$ and Mandarin $(\mathrm{n}=7)$. Mean age was 60.1 for patients $(\mathrm{SD}=14.4)$ and 53.6 for caregivers $(\mathrm{SD}=11.2)$. Participants were predominantly Chinese $(83.3 \%)$. Caregivers tended to be the spouse or the child of the patient. All patients were on chemotherapy, with $12.5 \%$ and $6.3 \%$ on additional radiotherapy and medication, respectively (see table 2).

Codes in patients' and caregivers' interviews were merged to produce five higher order themes: heightened sense of threat and risk, impact on healthcare experience, responsibility falls on oneself, striving for normalcy and sense of safety and trust. Themes were found to be highly consistent across both groups except for one subtheme unique to caregivers (ie, duty towards the patient) and one unique to patients (ie, beyond personal control). Illustrative quotes for each subtheme are presented in figure 1 and table 3 . 
Table 2 Sample sociodemographic and clinical characteristics

\begin{tabular}{lll} 
Characteristics & $\begin{array}{l}\text { Patients } \\
(\mathbf{n}=16)\end{array}$ & $\begin{array}{l}\text { Caregivers } \\
(\mathbf{n}=14)\end{array}$ \\
\hline Age in years, mean \pm SD & $60.1 \pm 14.4$ & $53.6 \pm 11.2$ \\
\hline Gender-female, $\mathbf{n}(\%)$ & $6(37.5)$ & $10(71.4)$ \\
Ethnicity (\%) & & \\
Chinese & 81.3 & 85.7 \\
Malay & 12.5 & 7.1 \\
Indian & 0 & 7.1 \\
Others & 6.3 & 0
\end{tabular}

Educational attainment (\%)

\begin{tabular}{lll} 
Primary school & 6.3 & 0 \\
\hline Secondary school & 56.3 & 35.7 \\
\hline Polytechnic diploma & 12.5 & 7.1 \\
\hline Graduate degree & 18.8 & 35.7 \\
\hline Postgraduate degree & 6.3 & 14.3 \\
\hline Other & 0 & 7.1
\end{tabular}

\section{Employment status (\%)}

\begin{tabular}{lll} 
Employed full time & 31.3 & 64.3 \\
\hline Employed half-time & 6.3 & 7.1 \\
\hline Retired & 56.3 & 7.1 \\
Homemaker & 0 & 21.4 \\
\hline Missing data & 6.3 & 0 \\
\hline Monthly personal income (\%) & & \\
\hline Below \$2500 & 18.8 & 7.1 \\
\$2500-\$4999 & 18.8 & 21.4 \\
\$5000-\$7500 & 6.3 & 21.4 \\
Above \$7500 & 6.3 & 21.4 \\
N/A (retired or homemaker) & 50.0 & 28.6
\end{tabular}

Relationship status (\%)

\begin{tabular}{lll} 
Married & 87.5 & 71.4 \\
\hline Divorced or widowed & 6.3 & 7.1 \\
\hline Single & 6.3 & 21.4
\end{tabular}

Relation to patient (\%)

Spouse

35.7

\begin{tabular}{|c|c|c|}
\hline \multicolumn{2}{|l|}{ Parent } & 7.1 \\
\hline \multicolumn{2}{|l|}{ Child } & 35.7 \\
\hline \multicolumn{2}{|l|}{ Sibling } & 14.3 \\
\hline \multicolumn{2}{|l|}{ Friend } & 7.1 \\
\hline \\
\hline \multicolumn{3}{|l|}{$\begin{array}{l}\text { Ireatment type (\%) } \\
\text { Chemotherapy only }\end{array}$} \\
\hline Chemotherapy and radiotherapy & \multicolumn{2}{|l|}{12.5} \\
\hline Chemotherapy and medication & \multicolumn{2}{|l|}{6.3} \\
\hline \multicolumn{3}{|l|}{ Cancer type (\%) } \\
\hline Colon & \multicolumn{2}{|l|}{31.3} \\
\hline Lung & \multicolumn{2}{|l|}{12.5} \\
\hline
\end{tabular}

Continued
Table 2 Continued

\begin{tabular}{lll}
\hline Characteristics & $\begin{array}{l}\text { Patients } \\
(\mathbf{n}=16)\end{array}$ & $\begin{array}{l}\text { Caregivers } \\
(\mathbf{n}=14)\end{array}$ \\
\hline Lymphoma & 12.5 & \\
\hline Prostate & 6.3 \\
\hline Pancreas & 6.3 \\
\hline Stomach & 6.3 \\
\hline Adrenal & 6.3 \\
\hline Brain & 6.3 \\
\hline Nose & 6.3 \\
\hline Germ cell tumour & 6.3 \\
\hline Cancer stage (\%) & \\
\hline I & 6.3 \\
\hline II & 12.5 \\
\hline III & 18.8 \\
\hline IV & 62.5 \\
\hline
\end{tabular}

Heightened sense of threat and risk

The first theme captured the heightened salience of the threat and risk posed by COVID-19, common across patients and caregivers. Three subthemes were identified: (1) vulnerability and fear, (2) uncertainty and (3) socially irresponsible others.

\section{Vulnerability and fear}

COVID-19 was regarded as a prominent source of threat that elicited fear, worry and perceptions of vulnerability. Both patients and caregivers recognised that patients were highly vulnerable to COVID-19 due to cancer, their treatment-induced immunosuppressed state and risk of exposure due to their need to access hospitals for treatment. Even at these early stages of pandemic, patients already viewed COVID-19 as a dangerous threat for them, feared infection and were pessimistic about prognosis of their changes for recovery if infected. 'The chances of me surviving, I think it's very slim lah. Because I will be

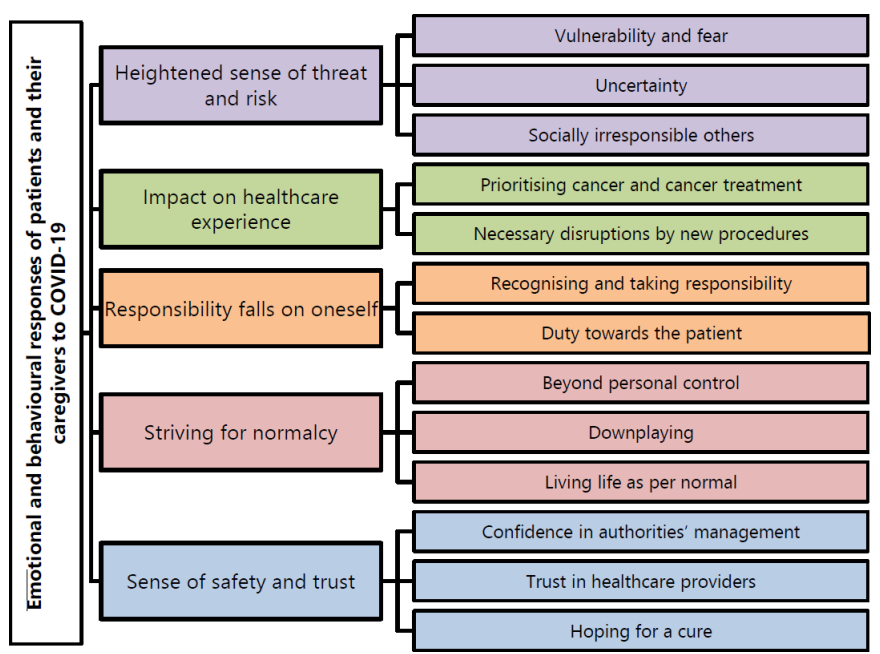

Figure 1 Thematic schema. 


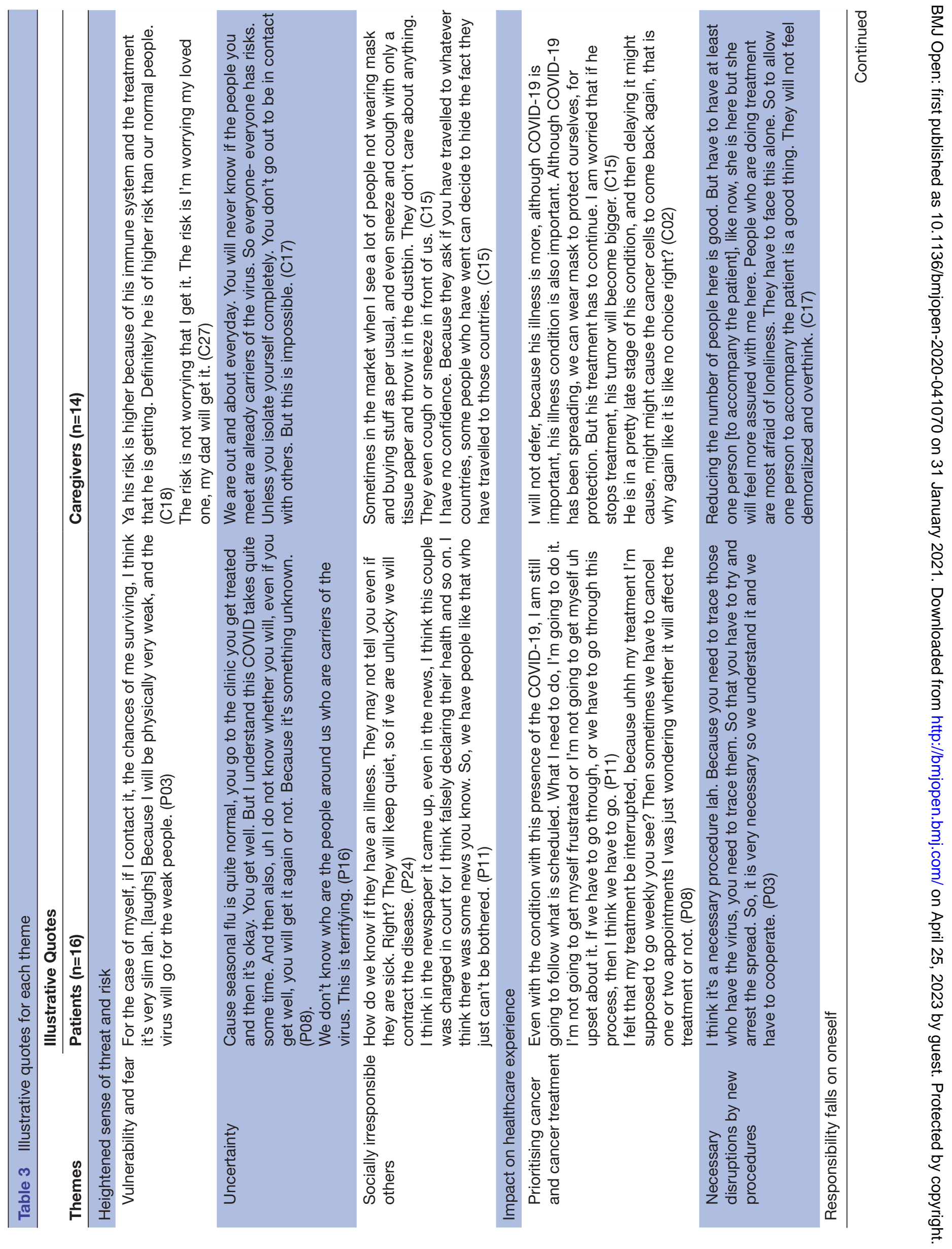




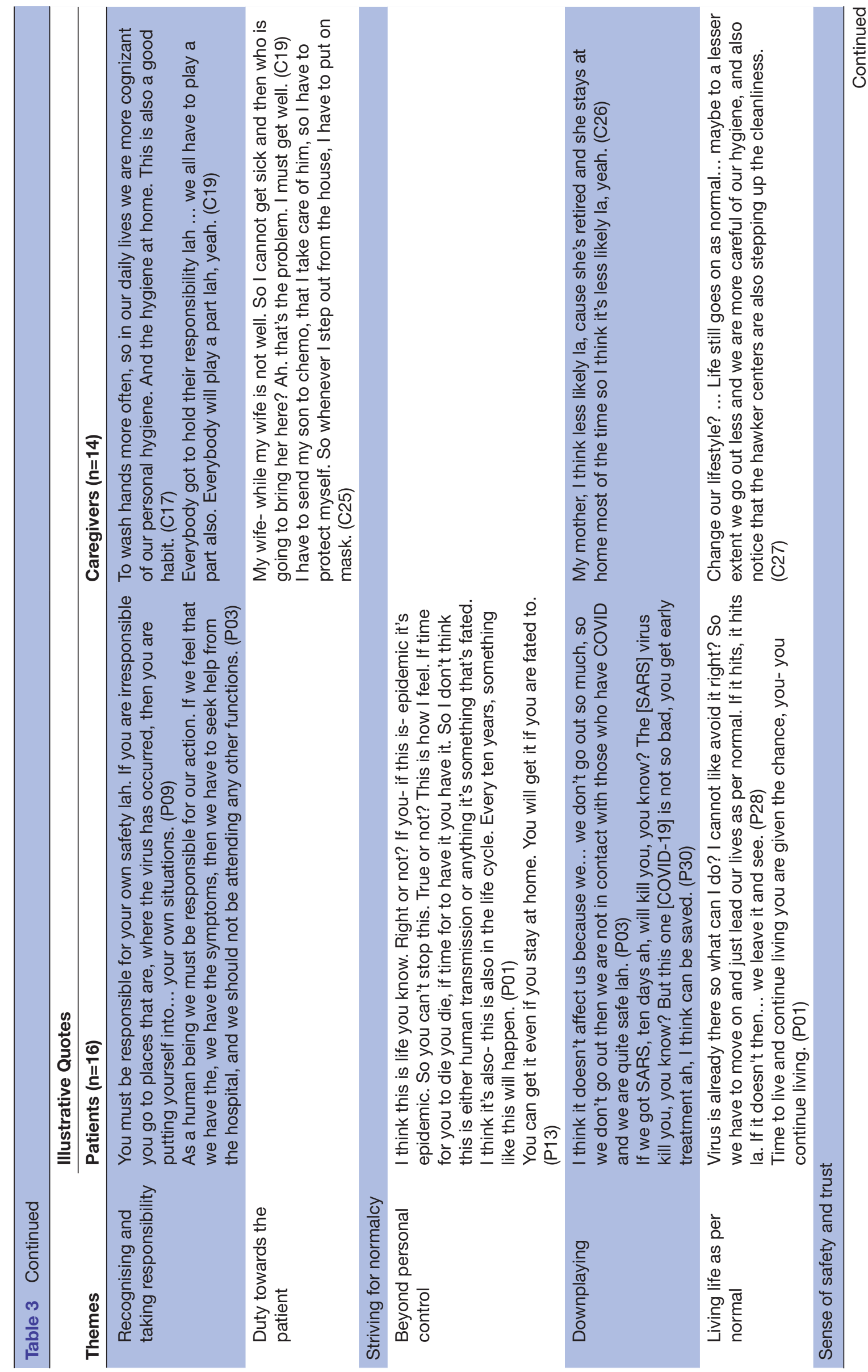




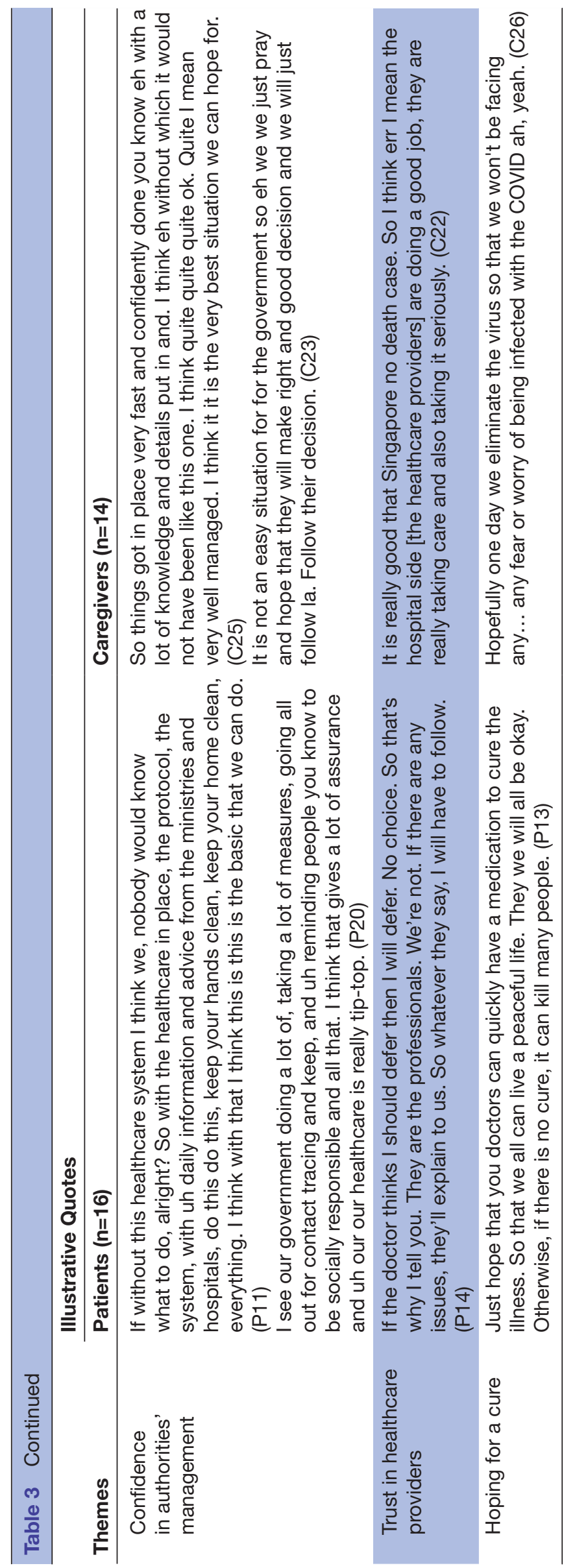

physically very weak, and the virus will go for the weak people' (P03). They worried about accessing hospitals and being around other patients and noted that they would like to minimise time spent at hospitals.

Caregivers however appeared unconcerned about their personal vulnerability to COVID-19 but expressed high anxiety and worry about patients. They worried over patients' risk and prognosis and prioritised the patients' health over themselves, 'The risk is not worrying that I get it. The risk is I'm worrying my loved one, my dad will get it' (C27).

\section{Uncertainty}

Being a new virus, the uncertainty surrounding COVID-19 intensified patients' and caregivers' threat perceptions. Participants discussed uncertainty in terms of the virus per se (clinical manifestations/severity, symptoms and transmission), the prognosis (course of pandemic, duration and numbers to be affected) and the broader implications of COVID-19 and related measures for personal finances or national/global economies.

Participants noted how little was known and understood about COVID-19 especially with regards to transmission and symptom presentation. They highlighted that the symptoms of COVID-19 may be too generic, vague or mild to recognise and respond in time and pondered about the possibility and threat of asymptomatic transmissions. As shared by one caregiver, 'you never know if the person beside you might have the illness' (C15).

There was also uncertainty about the course, trajectory and magnitude of the pandemic. Patients and caregivers were concerned about how long the COVID-19 situation would last, how many people would become infected and if/when a vaccine or treatment would become available. Linked to the uncertainly about future were the concerns about the broader long-term impact of COVID-19 and containment measures on finances and the economy. One patient remarked, 'Look at those doing business, they don't have business now. Nobody is coming out now. Who dares to come out?' (P13).

\section{Socially irresponsible others}

Both patients and caregivers attributed heightened threat to the irresponsible actions of other people. This was shaped by both media reports and first-hand accounts.

Patients and caregivers recounted media reports on members of public providing false declaration of travel history and worried that many others in community may potentially be deceitful, for example, not disclosing symptoms or travel history and providing inaccurate information. For instance, one patient raised an example of a couple charged in court for falsely declaring their health status (P11). These unlawful actions were viewed as immoral for impeding transmission containment measures and placing others at risk.

For patients and caregivers, socially irresponsible behaviours also included poor hygiene practices such as coughing or sneezing in front of others. Despite the 
government's recommendation at the time of interviews to only don masks when unwell, the lack of masks was still regarded as inconsiderate and socially irresponsible: 'Sometimes in the market when I see a lot of people not wearing mask and buying stuff as per usual... They don't care about anything. They even cough or sneeze in front of us' (C15). Participants had no confidence in others practising good hygiene, which amplified worry and perceived threat.

\section{Impact on healthcare experience}

The second theme comprised two subthemes: prioritising cancer and cancer treatment and necessary disruptions caused by new procedures.

\section{Prioritising cancer and cancer treatment}

Cancer and cancer treatment remained a top priority for both patients and caregivers despite the outbreak. While COVID-19 was regarded as a serious threat, it was not described to be as imminent or grave as cancer: "cancer is worse, it kills people. This COVID-19 is for you to take precaution' (P30). They were insistent in adhering to the patients' cancer treatment regime and opted not to defer for fear that deferment may worsen the cancer: 'if you deferred, there might be aggressive type of cancer that might that might come back' (C18). They discussed two potential treatment disruptions due to COVID-19. First, patients and caregivers expressed concerns that contracting COVID-19 would mean that cancer treatment may have to be postponed. Second, while active cancer treatment proceeded as usual, the suspension/limited operational capability of laboratory services may disrupt diagnostic services and delay subsequent treatment.

\section{Necessary disruptions by new procedures}

Several measures were implemented in response to COVID-19 but were seen as necessary to protect everybody: 'I think it's a necessary procedure lah. Because you need to trace those who have the virus... So that you have to try and arrest the spread. So, it is very necessary so we understand it and we have to cooperate' (P03). The screening stations led to slight delays to enter the premises, to which most responded by arriving earlier. Visiting was restricted to one visitor per patient and only during specified visiting hours. One inpatient lamented that his spouse could no longer keep him company overnight but acknowledged that it is a sacrifice he could make. In general, patients and caregivers appreciated the extra measures taken and accepted the associated minor inconveniences, dubbing them as troublesome but good procedures.

\section{Responsibility falls on oneself}

Both patients and caregiver emphasised the importance of own agency and taking responsibility to keep healthy. For caregivers, sense of responsibility included duty towards the patient.
Recognising and taking responsibility

Patients and caregivers were concordant in making behavioural adjustments to stay safe. These precautions primarily involved increasing hygiene practices, wearing masks, minimising social activities and proactively seeking out information related to COVID-19. There was great variability in social adjustment in response to COVID-19. This ranged from minimising exposure to crowds, only going out during off-peak hours, to staying home and avoiding social contact whenever possible. For patients, they reiterated the importance of self-reliance: 'now you have no choice, you can only protect yourself' (P29). Notably, many of these self-care and precautionary behaviours were already in place before COVID-19 as a result of living with cancer. 'I used to play golf, so I stopped golfing, so that, I used to meet my friends in the club. I cut that down. So...yes, because of my treatment I have, my social life has changed... So, whether there's COVID-19 or no COVID-19, it doesn't matter to me because, uh, my, my lifestyle has changed' (P03).

Besides personal behavioural adjustments, patients and caregivers recognised that managing COVID-19 required a collective effort and actions. They acknowledged that every individual had to play their part to practice responsible behaviours and comply with safety regulations.

\section{Duty towards the patient}

Caregivers expressed a strong sense of duty that comprised providing care for the patient, endorsing COVID-19 precautionary measures and self-care. First, caregivers took the initiative to ensure that the patient takes necessary precautions to reduce their risk of contracting COVID-19. Often, this occurs by actively enforcing or supporting patients' actions, such as practicing good hygiene, regular handwashing or reducing contact with crowds.

Second, caregivers will take their own precautions against COVID-19 to ensure that they do not contract COVID-19. The motivation to remain well was related to the need to continue providing care: 'I have to send my son to chemo, that I take care of him, so I have to protect myself' (C25). Some caregivers also reported striving to stay healthy to avoid being the carrier to pass the disease to the patient.

\section{Striving for normalcy}

The fourth theme encapsulates patients' and caregivers' cognitive and behavioural responses to preserve normalcy in their lives amidst the COVID-19 outbreak. They viewed the outbreak as beyond one's personal control, rationalised and downplayed threat and focused on living life as per normal.

\section{Beyond personal control}

Specific to patients, many spoke about their belief that circumstances related to COVID-19 were out of their personal control. They described an inability to exert control over contracting COVID-19: 'if it's really fated 
then you have no choice' (P16). This inevitability was present regardless of precautions: 'you can get it even if you stay at home. You will get it if you are fated to' (P13).

\section{Downplaying}

Despite facing the threat of COVID-19, patients and caregivers made attempts to downplay risks and personal relevance. They rationalised and extrapolated based on prior infectious outbreaks: 'SARS is more fatal. The COVID19 , if treated properly, is nothing much' (P07). Others likened the nature of COVID-19 to the common influenza and perceived possible recovery from COVID-19 should they contract it. While they recognised that patients were more vulnerable given their weaker immunity, many patients and caregivers downplayed the personal risks of COVID-19 due to them mostly staying home and always wearing masks when outside, which they report protects them from COVID-19. Many felt more assured by wearing masks in crowded spaces or hospitals.

\section{Living life as per normal}

Patients and caregivers both described having continued with daily routines amidst the COVID-19 situation: 'life still goes on, it doesn't change much, except that we have to be more vigilant' (P03). Some reasoned that life had to go on and continued with various activities including grocery shopping, attending religious services or meeting friends. Others adopted more precautions-notably stepping up hygiene practices and wearing masks—but generally perceived that COVID-19 had no change to their life. Patients also described minimal disruptions to cancer treatment: 'I have to prepare myself [for the appointment] and go earlier. So that's about it the only thing' (P08).

\section{Sense of safety and trust}

The final theme reflects the general perception of safety and trust patients and caregivers held in authorities and healthcare providers. Some also expressed hope for cure or vaccine for COVID-19.

\section{Confidence in authorities' management}

Patients and caregivers expressed huge confidence in how the local government and healthcare institutions had managed the COVID-19 outbreak. They reflected that the local COVID-19 situation was kept under control and articulated a willingness to comply with government directives: 'I'm fine as long as we abide, because we feel that we are very safe- it's well managed here' (C10). Many felt encouraged by the extensive contact tracing and quarantine measures conducted to ringfence potential new cases. Others were satisfied with the clear dissemination of official information that involved regular updates on new confirmed cases. Patients and caregivers also spoke about feeling assured by the high healthcare standards and found it safer to be in the hospital.

\section{Trust in healthcare providers}

Healthcare providers were regarded as highly competent by both patients and caregivers. This competence was described broadly to encompass several aspects from managing cancer treatment, treating COVID-19 to maintaining good hygiene standards. Many commended healthcare providers and were cognizant of their sacrifices, illustrated in statements like 'they're working longer hours... so fatigue comes in, but they don't show it when they're on duty' (P24). Healthcare providers were also relied on for guidance and advice, especially regarding cancer treatment.

\section{Hoping for a cure}

Notably, patients and caregivers spoke about wanting a cure or a solution to the COVID-19 situation. They hoped that authorities would successfully develop a treatment or vaccine for COVID-19: "just hope that you doctors can quickly have a medication to cure the illness. So that we all can live a peaceful life' (P13).

\section{DISCUSSION}

The COVID-19 pandemic has brought about changes in all domains of life including healthcare, leaving an emotional toll on healthcare users and healthcare providers alike. While clinical efforts are duly directed towards those considered more vulnerable, the scarce research on patient populations cannot adequately inform health service optimisation during these extraordinary times. This study attempted to bridge the gap by exploring the emotional and behavioural impact of COVID-19 on patients and caregivers during early stages of the outbreak in Singapore.

Five themes were generated that were salient in both patient and caregiver accounts: heightened sense of threat and risk, impact on healthcare experience, responsibility falls on oneself, striving of normalcy and sense of safety and trust. The themes painted a diverse and seemingly contradictory experience. Heightened threat induced by vulnerability and fear, uncertainty and irresponsible others was countered with perceptions of safety and trust towards healthcare providers alongside their own efforts to re-establish normalcy. Among respondents in China, greater satisfaction with risk communication, that is, provision of timely and credible information by health authorities about COVID-19, was found to be associated with subsequent reduced anxiety and emotional contagion. ${ }^{27}$ Perceptions of safety in our sample therefore may have been attributed to prompt risk communication by local authorities. This in turn likely helped to mitigate but not fully eliminate threat perceptions. This thematic diversity underscores that patients' and caregivers' experiences amid the outbreak are multifaceted and nuanced.

Living with and managing treatment for cancer is an emotionally charged journey that has intensified during the pandemic. Dominating the accounts was a heightened perception of threat specific to COVID-19, adding 
to but not superseding the threat related to cancer. Heightened threat was attributed to uncertainty, limited understanding of virus and disease course and potential contagion due to socially irresponsible others, as shown in prior infectious disease outbreaks. ${ }^{28}$ COVID-19 was deemed more threatening for patients as their frail health and compromised immunity made them more vulnerable to infection and poorer prognosis, as noted with other patient groups during SARS and H1N1. ${ }^{29} 30$ This threat of COVID-19 was interlinked with worry and fear. Cancer and need for treatment compounded these fears as both parties perceived that proceeding with cancer treatment was dependent on patients' good health. The duality of the threat posed by COVID-19 in directly compromising health and disrupting cancer treatment had elicited anticipatory anxiety among both patients and caregivers. Both groups were adamant in prioritising cancer and would not consider deferment of treatment unless advised by their healthcare providers. This contrasts reports in other (non-cancer) patient groups during SARS and Ebola. ${ }^{1011}$ Prioritising cancer treatment could be regarded as an extension of taking responsibility for one's (or the patient's) health; besides practising appropriate precautionary measures, both patients and caregivers acknowledge that they had to comply with treatment demands to manage the patient's condition.

Counterbalancing the threat of COVID-19, patients and caregivers expressed safety and trust in regulatory measures and stepped up actions of personal responsibility and actions to maintain normalcy. ${ }^{31}$ They detailed behaviours such as handwashing, avoiding social interactions and crowds or wearing of masks to reduce likelihood of infection. For some, these behaviours had already been cultivated into established routines prior to COVID-19 due to cancer. They both emphasised the importance of playing their part for the collective good. Unique to caregivers was an unwavering duty towards patients that encompassed care towards self and patients. The pandemic had spurred caregivers to be more conscientious about their own health to maintain their capacity to care for patients. However, this increased health surveillance can lead to additional burden, stress and negatively affect caregivers' health. ${ }^{32} 33$

To navigate the pandemic, patients and caregivers strived for normalcy. This was manifested as both cognitive processes and behaviours, both of which could be construed as emotion-focused or avoidance coping. ${ }^{34}$ Downplaying risk involved a reassurance of safety that was linked to behaviours such as staying home or wearing masks, or prior experience with SARS. Patients discussed COVID-19 as beyond their control (often using the term 'fated') that prompts them to redirect attention on living life and treatment. This suggests in the face of an unpredictable and novel threat, fatalism may be adaptive and reflect acceptance of the situation. Patients' and their caregivers' experiences with cancer could have conferred a general hardiness or resilience ${ }^{35} 36$ that extended to their experience with COVID-19. These cognitive and behavioural processes involved an active disengagement from the threat posed by COVID-19, allowing for patients and caregivers to self-soothe and regulate their emotions.

The sense of safety and trust towards authorities also buffered the heightened sense of threat and risk and provided a semblance of normalcy. During data collection, the number of confirmed cases in Singapore bordered on 200 with no fatalities and ranged from 1 to 12 new cases each day. These relatively low numbers may have boosted patients' and caregivers' confidence in accessing healthcare. Safety was discussed both as a general feeling of security and preparedness by authorities/hospitals and trust towards healthcare providers. Patients and caregivers held a deep appreciation for healthcare providers for their contributions during the pandemic and relied on them to navigate health-related matters.

\section{Clinical implications}

Findings have important implications for clinical practice. The priority placed cancer treatment over COVID-19 threats comprises a major aspect of patients' and caregivers' healthcare experience. Evidently, access to cancer treatment remains at the forefront of their agenda. Crucially, this underscores the need for continuity in health services. Services need to incorporate psychosocial support as patients report elevated threat, worry and fear related to COVID-19 and its impact on cancer management. Efforts should target both general COVID-19 concerns that pertain to the whole community and cancerspecific concerns about COVID-19 unique to individuals stricken by cancer. Cancer-specific concerns involving disruptions to treatment-related procedures cause anticipatory anxiety that may compromise emotional wellbeing. These concerns may not be proactively shared in consultations but should be elicited and addressed. It may then be useful to leverage on the firm trust and confidence placed in oncology healthcare providers that strategically positions them to support such conversations. To assuage general COVID-19 concerns, many of which involve risk of heightened exposure to COVID-19, alternative arrangements such as teleconsultations provide patients and caregivers with a safer and more convenient medium to access health services remotely. These platforms become even more pertinent during the times of pandemic with social distancing policies and visitor limitations. ${ }^{37}$

Caregivers should also be supported to buffer against burnout. Clinicians may consider inviting caregivers to attend patients' consultation sessions and allocate some time to address caregivers' concerns in session. Engaging caregivers directly in session alerts clinicians to signs of elevated psychological distress that may warrant a referral to medical social workers or psychologists for counselling. Ensuring caregiver well-being has important implications for the patients' care. Caregiver support in the form of dyadic coping influences the level of psychological distress and adjustment in patients across various cancer contexts. ${ }^{38-41}$ Finally, while institutional safety measures 
implemented may incur additional inconveniences, our study suggests it bolsters confidence in the institution and provide patients and caregivers with a sense of safety.

\section{Study limitations}

Possible limitations related to face-to-face qualitative interviews exist. Selection bias may be present, as patients and caregivers who do not present at NCCS would not have been approached and been indirectly excluded from the study. Social desirability bias may also be present, as participants selectively share and elaborate opinions that they perceive to be more acceptable or socially desirable (eg, prioritising cancer vs rejecting treatment). Lastly, all interviews had to be conducted by NCCS staff as nonNCCS staff were not permitted to enter the premises as part of COVID-19 management measures. We have sought to minimise potential bias by engaging research coordinators and one oncologist not involved in direct care of the patients they interviewed.

At the time of writing, local cases have breached the 30 000 mark. As the present study was conducted during the earlier stages of the pandemic in Singapore, its impact is likely to have evolved as the pandemic unfolds. Future work can seek to elucidate the impact of the pandemic at later phases and from different population groups, particularly those who may have opted to stray from treatment care. This would serve to inform and improve healthrelated policies to better meet the needs of these healthcare users.

The threat induced by COVID-19 has amplified concerns surrounding cancer treatment among patients with cancer and their caregivers. Patients and caregivers intensify precautionary behaviours and strive to maintain normalcy but worry of risks to patients and impact of the pandemic on cancer treatment plans. Digital mental health services led by healthcare providers could serve address these specific concerns and provide a sustained line of support to patients and caregivers during these tumultuous times.

Acknowledgements The authors would like to thank Dr Tonia Griva, the healthcare professionals at National Cancer Centre Singapore, and all study participants for their support in the research study.

Contributors KYYN, DI, ZZSG, ZYC, JMXC, KG and JYYN conceived, designed the study. KYYN, DI and SMF collected the data. JMXC, ZZSG, ZYC, KYYN and $\mathrm{KG}$ analysed the data. All authors interpreted the data and were involved in the development, review and approval of the manuscript.

Funding This work was supported by the National Medical Research Council Clinician Scientist Award (NMRC/CSA-INV/0017/2017) and administered by the Singapore Ministry of Health's National Medical Research Council.

Competing interests None declared.

Patient consent for publication Not required.

Ethics approval Ethics was approved by Singhealth Centralised Institutional Review Board (CIRB reference: 2020/2155).

Provenance and peer review Not commissioned; externally peer reviewed.

Data availability statement Data are available on reasonable request. The thematic data that support the findings of this present study are available from the corresponding author on reasonable request.
Supplemental material This content has been supplied by the author(s). It has not been vetted by BMJ Publishing Group Limited (BMJ) and may not have been peer-reviewed. Any opinions or recommendations discussed are solely those of the author(s) and are not endorsed by BMJ. BMJ disclaims all liability and responsibility arising from any reliance placed on the content. Where the content includes any translated material, BMJ does not warrant the accuracy and reliability of the translations (including but not limited to local regulations, clinical guidelines, terminology, drug names and drug dosages), and is not responsible for any error and/or omissions arising from translation and adaptation or otherwise.

Open access This is an open access article distributed in accordance with the Creative Commons Attribution Non Commercial (CC BY-NC 4.0) license, which permits others to distribute, remix, adapt, build upon this work non-commercially, and license their derivative works on different terms, provided the original work is properly cited, appropriate credit is given, any changes made indicated, and the use is non-commercial. See: http://creativecommons.org/licenses/by-nc/4.0/.

ORCID iDs

Zi Yang Chua http://orcid.org/0000-0003-2903-5779

Konstadina Griva http://orcid.org/0000-0001-8173-5663

\section{REFERENCES}

1 Lu T-H, Chou Y-J, Liou C-S. Impact of SARS on healthcare utilization by disease categories: implications for delivery of healthcare services. Health Policy 2007;83:375-81.

2 Teasdale E, Yardley L. Understanding responses to government health recommendations: public perceptions of government advice for managing the H1N1 (swine flu) influenza pandemic. Patient Educ Couns 2011;85:413-8. doi:10.1016/j.pec.2010.12.026

3 Wong ELY, Wong SYS, Lee N, et al. Healthcare workers' duty concerns of working in the isolation ward during the novel H1N1 pandemic. J Clin Nurs 2012;21:1466-75.

4 Cava MA, Fay KE, Beanlands HJ, et al. Risk perception and compliance with quarantine during the SARS outbreak. J Nurs Scholarsh 2005;37:343-7.

5 Tiwari A, Chan S, Wong A, et al. Severe acute respiratory syndrome (SARS) in Hong Kong: patients' experiences. Nurs Outlook 2003;51:212-9.

6 Hategan A, Abdurrahman M. Hidden in plain sight: addressing the unique needs of high-risk psychiatric populations during the COVID-19 pandemic. Psychiatry Clin Neurosci 2020;74:439.

7 Shigemura J, Ursano RJ, Morganstein JC, et al. Public responses to the novel 2019 coronavirus (2019-nCoV) in Japan: mental health consequences and target populations. Psychiatry Clin Neurosci 2020;74:281-2. doi:10.1111/pcn.12988

8 Sani G, Janiri D, Di Nicola M, et al. Mental health during and after the COVID-19 emergency in Italy. Psychiatry Clin Neurosci 2020;74:372.

9 Zhu X, Wu S, Miao D, et al. Changes in emotion of the Chinese public in regard to the SARS period. Soc Behav Pers 2008;36:447-54.

10 Chang $\mathrm{H}-\mathrm{J}$, Huang $\mathrm{N}$, Lee $\mathrm{C}-\mathrm{H}$, et al. The impact of the SARS epidemic on the utilization of medical services: SARS and the fear of SARS. Am J Public Health 2004;94:562-4.

11 Carter SE, O'Reilly M, Walden V, et al. Barriers and Enablers to treatment-seeking behavior and causes of high-risk practices in Ebola: a case study from Sierra Leone. $J$ Health Commun 2017;22:31-8.

12 Liang W, Guan W, Chen R, et al. Cancer patients in SARSCoV-2 infection: a nationwide analysis in China. Lancet Oncol 2020;21:335-7.

13 Williamson E, Walker AJ, Bhaskaran KJ. OpenSAFELY: factors associated with COVID-19-related Hospital death in the linked electronic health records of 17 million adult NHS patients. medRxiv 2020.

14 Singer S. Psychosocial impact of cancer. In: Goerling U, Mehnert A, eds. Recent results in cancer research. Cham: Springer International Publishing, 2018: 1-11.

15 Zabora J, BrintzenhofeSzoc K, Curbow B, et al. The prevalence of psychological distress by cancer site. Psychooncology 2001;10:19-28.

16 Costanzo ES, Ryff CD, Singer BH. Psychosocial adjustment among cancer survivors: findings from a national survey of health and wellbeing. Health Psychol 2009;28:147-56.

17 Caruso R, Nanni MG, Riba MB, et al. The burden of psychosocial morbidity related to cancer: patient and family issues. Int Rev Psychiatry 2017;29:389-402.

18 Northouse L, Williams A-leila, Given B, et al. Psychosocial care for family caregivers of patients with cancer. J Clin Oncol 2012;30:1227-34. 
19 Kim Y, Baker F, Spillers RL, et al. Psychological adjustment of cancer caregivers with multiple roles. Psychooncology 2006;15:795-804.

20 Archer S, Holch P, Armes J, et al. "No turning back" Psychooncology in the time of COVID-19: Insights from a survey of UK professionals. Psychooncology 2020;29:1430-5.

21 Tong A, Sainsbury P, Craig J. Consolidated criteria for reporting qualitative research (COREQ): a 32-item checklist for interviews and focus groups. Int J Qual Health Care 2007;19:349-57.

22 Creswell JW. Qualitative inquiry and research design, 2013.

23 Wadsworth Y. What is participatory action research? Action Res Int 1998:1-23.

24 Braun V, Clarke V. Using thematic analysis in psychology. Qual Res Psychol 2006;3:77-101.

25 Elo S, Kääriäinen M, Kanste O. Qualitative content analysis: a focus on Trustworthiness. SAGE Open 2014;4.

26 Korstjens I, Moser A. Series: practical guidance to qualitative research. Part 4: Trustworthiness and publishing. Eur J Gen Pract 2018;24:120-4

27 Jin Z, Zhao K-B, Xia Y-Y, et al. Relationship between psychological responses and the appraisal of risk communication during the early phase of the COVID-19 pandemic: a two-wave study of community residents in China. Front Public Health 2020;8:550220.

28 Teasdale E, Santer M, Geraghty AWA, et al. Public perceptions of non-pharmaceutical interventions for reducing transmission of respiratory infection: systematic review and synthesis of qualitative studies. BMC Public Health 2014;14:589.

29 Siu JY-M. Another nightmare after SARS: knowledge perceptions of and overcoming strategies for $\mathrm{H} 1 \mathrm{~N} 1$ influenza among chronic renal disease patients in Hong Kong. Qual Health Res 2010;20:893-904.

30 Rubin GJ, Amlôt R, Carter H, et al. Reassuring and managing patients with concerns about swine flu: qualitative interviews with callers to NHS direct. BMC Public Health 2010;10:451.
31 Lazarus RS, Folkman S. Transactional theory and research on emotions and coping. Eur J Pers 1987;1:141-69.

32 Hodges LJ, Humphris GM, Macfarlane G. A meta-analytic investigation of the relationship between the psychological distress of cancer patients and their carers. Soc Sci Med 2005;60:1-12.

33 Bevans M, Sternberg EM. Caregiving burden, stress, and health effects among family caregivers of adult cancer patients. JAMA 2012;307:398.

34 Leventhal H, Brissette I, Leventhal EA. The common-sense model of self-regulation of health and illness. In: The self-regulation of health and illness behaviour. In, 2012.

35 Seiler A, Jenewein J. Resilience in cancer patients. Front Psychiatry 2019;10:208.

36 Walshe C, Roberts D, Appleton L, et al. Coping well with advanced cancer: a serial qualitative interview study with patients and family carers. PLoS One 2017;12:e0169071-25.

37 Blackstone E, Lipson AR, Douglas SL. Closer: a videoconference intervention for distance caregivers of cancer patients. Res Nurs Health 2019;42:256-63.

38 Regan TW, Lambert SD, Kelly B, et al. Cross-sectional relationships between dyadic coping and anxiety, depression, and relationship satisfaction for patients with prostate cancer and their spouses. Patient Educ Couns 2014;96:120-7. doi:10.1016/j.pec.2014.04.010

39 Badr H, Herbert K, Bonnen MD, et al. Dyadic coping in patients undergoing radiotherapy for head and neck cancer and their spouses. Front Psychol 2018;9:1780.

40 Feldman BN, Broussard CA. Men's adjustment to their partners' breast cancer: a dyadic coping perspective. Health Soc Work 2006;31:117-27.

41 Van Schoors M, De Paepe AL, Lemiere J, et al. Family adjustment when facing pediatric cancer: the role of parental psychological flexibility, Dyadic coping, and network support. Front Psychol 2019;10:1-12. 